Check for updates

Cite this: RSC Adv., 2017, 7, 51130

Received 15th September 2017 Accepted 28th October 2017

DOI: $10.1039 / \mathrm{c} 7 \mathrm{ra10262c}$

rsc.li/rsc-advances

\section{One pot green preparation of Seabuckthorn silver nanoparticles (SBTCAgNPs) featuring high stability and longevity, antibacterial, antioxidant potential: a nano disinfectant future perspective}

\author{
Thiyagarajan Kalaiyarasan, D Vijay K. Bharti* and O. P. Chaurasia
}

In recent years antimicrobial resistance (AMR) threatens the effective prevention and treatment of an everincreasing range of infections caused by bacteria, parasites, viruses, fungi and development of effective therapeutics is a major challenge to the scientific community. Silver Nanoparticles (AgNPs) well know antimicrobials, but limited information available on the effect of 'Phytosynthesis' and there clinical applications. Phytochemicals occluded in Seabuckthorn (SBT) have been extensively used as dietary supplements and as natural pharmaceuticals in the treatment of various diseases including human cancer. In this context, we present a kind of eco-friendly, economically viable, possible to commercialization, free from chemical agents and rapid preparation of SBT@AgNPs employing the leaves extracts of Seabuckthorn (SBT). The SBT leaf extracts the rich source of organic acids and inorganic compounds may be envisaged for the formation of the SBT@AgNPs at room temperature ( $25^{\circ} \mathrm{C} \pm 1.5$ for 60 minutes). Physicochemical properties of synthesized nanoparticles were characterized using various spectroscopic techniques. The results depicted that SBT leaf mediated SBTaAgNPs are spherical with an average particles size of $\sim 10-40 \mathrm{~nm}$. The present SBTaAgNPs has shown long time stability (one year), indicated by their unchanged SPR band, TEM image, and zeta-potential value. The evaluation of antimicrobial properties of SBTAAgNPs indicated significant inhibition of Gram-positive and Gram-negative bacterial strains even at much lower than the minimum inhibitory concentration $\left(2 \mu \mathrm{g} \mathrm{mL}{ }^{-1}\right)$. Live and dead bacterial assay with confocal microscopy image demonstrated that the SBTaAgNPs disrupt the bacterial cell membrane which subsequently results in cellular material leakage and cell death. Antioxidant assay results suggest that DPPH radical scavengers increased more than 10 fold efficacy as compared to SBT leaves extract. Interestingly, this study also demonstrated that SBT@AgNPs impregnated paper preparation and there antibacterial activity against bacterial cocktail, the results shown that higher than the commercially available medicated dressing materials and deterioration and longevity of SBTaAgNPs impregnated paper also studied. Overall, the present study has disclosed a sustainable and green preparation of SBTaAgNPs and depicted their antibacterial, antioxidant agents and routine infectioncontrol in day to day life. We strongly believe that SBT@AgNPs has great potential as an effective antibacterial tool for controlling and prevention of currently emerging bacterial infections in everyday life.

\section{Introduction}

Bacterial outbreaks originating from human contact, food poisoning, contaminated water reservoirs, and bioterrorism represent a major global public health threat and socioeconomic loss for millions of people. ${ }^{1,2}$ Bacterial infection has been effectively controlled by the middle of the $1900 \mathrm{~s}$ after the discovery of various antibiotics e.g. penicillin, tetracycline, streptomycin, vancomycin, etc. ${ }^{3}$ It has been estimated that $70 \%$ of hospital-acquired infection (HAI), resistance to one of the

Defence Institute of High Altitude Research (DIHAR), DRDO, Leh-Ladakh-194101, J\&K, India. E-mail: vijaykbharti@rediffmail.com; Fax: +91-172-2638500; Tel: +91-172-2638900 antimicrobials used for treatment of microbial borne diseases. ${ }^{4-7}$ Which has developed or acquired resistance to nearly all antibiotics. ${ }^{3,8}$ This ongoing race between the emergence of drug resistance and the development of novel antimicrobial agents, microbes appear to be pulling ahead? Moreover, the development of new antibiotics has grossly fallen behind the speed at which the fast and frequent development of antibiotic resistance seen in the microbial borne diseases. ${ }^{3,9,10}$ Therefore, various study investigating new antimicrobials for effective antibacterial strategies to improve antibiotic therapy, which is recognized globally as a major focus area of research priority. Over the past few years increasing research efforts have been devoted to exploring the nanomaterials based antimicrobials to overcome 
these problems of multidrug resistant, due to their broad spectrum of antimicrobial activity. For example, various nanomaterials like carbon nanotubes, Ag, Au, Cu, $\mathrm{ZnO}, \mathrm{TiO}_{2}$, chitosan, cationic peptides, etc. possess antimicrobial activities and therefore have been used for the treatment of infectious diseases. ${ }^{\mathbf{1 1 - 1 7}}$ So far, around 100 nanomedicine products already approved for clinical use and approximately 10 nanoparticlebased products have been marketed for bacterial diagnosis, antibiotic delivery, and medical devices. ${ }^{18-22}$ In comparison with conventional antibiotic agents which currently utilize everyday clinic practice, nanoantibiotics exhibit many advantages like targeted delivery, sustained drug release, enhanced cellular bioavailability, solubility, and minimal side effects. More importantly, nanomaterial possesses the additional possibility to combat antibiotic resistance by compromising existing resistance mechanisms displayed in 'superbugs'. ${ }^{3}$ Among different nanomaterials, silver nanomaterials has great attention among the researcher due to their multifaceted antibacterial mechanism which could provide a powerful weapon against a broad range of bacteria including drug resistant microbes. However, complex and tedious preparation methods of nanomaterials, their poor stability in different environment (i.e. $\mathrm{pH}$, ionic strength, and temperature), poor long-term antibacterial efficiency, low yields, and cytotoxicity towards mammalian cells have restricted their application. ${ }^{23}$ In this context, biogenic preparation nanomaterials has great attention among the researchers in order to avoids the use of toxic and hazardous chemicals which is increasing demand for the purpose of 'green chemistry'. Recently, the preparations of nanoparticles using microorganisms like bacteria, fungi, actinomycetes, yeasts and viruses has been reported. ${ }^{24-31}$ However, in comparison with microbial synthesis of nanoparticles, phytosynthesis methods using plant extracts is more viable and can be up-scaled for commercial preparation and of free from the complex and multistep processes such as microbial isolation, culturing, time consuming, maintenance, etc. ${ }^{32-35}$ Further, this method is more rapid, the rate of reaction is faster than microbes, the nanoparticles produced by phytosynthesis are more stable, economically viable and effortlessly could be employed for the large scale synthesis. ${ }^{34,35}$ With this background, several studies reported that Seabuckthorn (Hippophae rhamnoides L.) leaves extract are rich in many bioactive compounds and it has been used for various pharmacological activities including antibacterial and antioxidants properties. ${ }^{36}$ Therefore, our aim in the present study was (1) to synthesis AgNPs using Seabuckthorn (SBT) leaves extract and examines their stability and longevity after different period of storage, (2) evaluation of their antibacterial potential against Gram-positive and Gram-negative bacteria, and (3) preparation of AgNPs impregnated paper for point-of care uses. As far we know this is the first attempt to prepare nanoparticles by this plant has not been reported.

\section{Experimental methods}

\section{Materials}

Silver nitrate $\left(\mathrm{AgNO}_{3}\right)$, acridine orange (AO), propidium iodide (PI), sodium hydroxide $(\mathrm{NaOH})$, hydrochloric acid $(\mathrm{HCl}), \mathrm{DPPH}$, ethanol of AR grade were acquired from Sigma-Aldrich and was used as obtained without further purification. In all the experiments, Milli-Q water $(18.20 \Omega \mathrm{cm})$ was used to carry out all the experiments.

Furthermore, for antibacterial study, bacterial strains of Gram-negative bacteria Salmonella enterica (MTCC 3219), Salmonella typhimurium (MTCC 3224), Escherichia coli (MTCC062), Pseudomonas aeruginosa (MTCC 424) and Gram-positive bacteria Bacillus subtilis (MTCC 0211), were acquired from Institute of Microbial Technology (IMTECH), Chandigarh, Punjab, India. The strains were subcultured every 28 days to maintain cell viability, Salmonella Sps by Brain-heart infusion medium (BHI) and other strains are nutrient agar (NA) and stored at $4{ }^{\circ} \mathrm{C}$. All the microbial culture media were acquired from Himedia, India.

\section{Plant collection}

Fresh leaves (Hippophae rhamnoides L.) were collected in august 2015 in Leh, India, and identified by Dr O. P. Chaurasia, from our experimental plot, Division Medicinal and Aromatic Plant, DRDO-DIHAR. Voucher specimens are preserved in the laboratory (DRDO-DIHAR, Base lab, Chandigarh, India). Leaves are washed with double-distilled water for several times to make it free from dust particles and then dried at room temperature $\left(25^{\circ} \mathrm{C} \pm 0.5\right)$ for three days.

\section{Preparation of Seabuckthorn leaves extract}

Dried Seabuckthorn (SBT) leaves chopped into small pieces and $10 \mathrm{~g}$ of leaves transferred into Erlenmeyer flask (Infusil India private limited) containing $100 \mathrm{~mL}$ Milli-Q water and maintained at $50{ }^{\circ} \mathrm{C}$ in hot plate (Cole-Parmer, India) for $30 \mathrm{~min}$ then cooled to room temperature and filter through the Whatman No. 1 paper, and harvested leaves extract $\mathrm{pH}$ was 5.9. In order to get dried leaf power, the leaf extracts were lyophilized (FreezeDrying: Free Zone Plus, US) with vacuum (0.050 mBar) for 48 hours and thereafter dried leaf powder was stored at $4{ }^{\circ} \mathrm{C}$ for until further use. This dried leaf powder was used for the NPs synthesis.

\section{Synthesis of SBT@AgNPs nanoparticles}

At the onset, for the synthesis of NPs, varying concentration (i.e. 0.5 to $2.0 \mathrm{mg}$ ) of lyophilized Seabuckthorn leaf powder were added into four different round bottomed flasks contain $100 \mathrm{~mL}$ of $1000 \mathrm{ppm} \mathrm{AgNO}_{3}$ solution each, the solution stirring with magnetic stirrer for 15 minutes at $100 \mathrm{rpm}$ then the mixture was incubated for $24 \mathrm{~h}$ at room temperature. The color changes observed by the naked eye from harry yellow to brown within 30 minutes, after the incubation period the NPs formation were analyzed by UV-visible spectroscopy. In order to evaluate the stability of NPs, the synthesized NPs was poured into amber polypropylene bottles (Tarsons Products Pvt. Ltd. Kolkata, India), covered with aluminum foil and stored in the dark room (away from light) temperature at $25.0 \pm 2.0{ }^{\circ} \mathrm{C}$ in the laboratory for 30 days. Periodical visible inspection and UVspectroscopy examination were carried during the storage period. The results showed a clear difference in their efficacy in 
producing NPs; lyophilized Seabuckthorn leaf powder ( $2 \mathrm{mg}$ ) of only produced stable NPs and spectra with wavelength maximum $\left(\lambda_{\max }\right) 430 \mathrm{~nm}$. The other concentration of Seabuckthorn leaf powder used for NPs synthesis precipitated during the storage time, therefore we did not consider for further analysis. Based on the results, we take in account the NPs synthesis using $2 \mathrm{mg}$ of Seabuckthorn leaf powder further investigation. The NPs centrifuged at $10000 \mathrm{rpm}$ for 20 minutes and washed thrice with distilled water. The precipitate was desiccated at $50{ }^{\circ} \mathrm{C}$ $24 \mathrm{~h}$. The dried SBT@AgNPs was used for characterization and other studies present in the paper.

\section{Characterization of the SBT@AgNPs}

To know the optical property of bio synthesized SBT@AgNPs were analyzed using UV spectrophotometer (Shimadzu UV2600) at room temperature operated at a resolution of $1 \mathrm{~nm}$ quartz cuvette from $230-800 \mathrm{~nm}$ ranges. The micrographs of Transmission electron microscope (TEM) and High-resolution Transmission electron microscope (HRTEM) was performed with JEOL JEM-2100 (200 kV) microscopy. The elements in the nanocomposite were analyzed using an energy dispersive X-ray (EDX) spectral analyzer. The dynamic light scattering and zeta

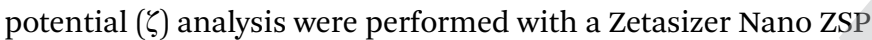
(Malvern, UK) instrument. Fourier transform infrared spectroscopy (FTIR), employed to identify the functional groups, FTIR spectra were recorded in the range from 4000 to $400 \mathrm{~cm}^{-1}$ using a Spectrum RX-IFTIR (Perkin Elmer Massachusetts, USA).

Antimicrobial assay. Antibacterial assay was employed using agar well diffusion technique, briefly, freshly grown bacterial strains (Salmonella typhimurium, Salmonella enterica) species in Brain heart infusion agar slants were inoculated in Brain heart infusion broth (BHI-B) and incubated at $37{ }^{\circ} \mathrm{C}$ with $120 \mathrm{rpm}$. Thereafter, cells were harvested from early stationary phase (12 to 16 hours) by centrifugation (6000 rpm for $10 \mathrm{~min}$ ) and washed three times with phosphate buffer (10 mM, pH 7.2). The cell pellets were finally resuspended in the same phosphate buffer to obtain the cell density of $0.1 \mathrm{OD}$ at $600 \mathrm{~nm}$ (optical density) approximately $10^{5} \mathrm{CFU} \mathrm{mL}^{-1}$. Then, $100 \mu \mathrm{L}$ of the bacterial suspension was spread uniformly on BHI plates $(9.0 \mathrm{~cm} \times 9.0 \mathrm{~cm})$ and the plates were incubated at $37^{\circ} \mathrm{C}$ for 30 minutes. Then, a hole with a diameter of $8 \mathrm{~mm}$ has punched aseptically with a sterile cork borer (Himedia, Mumbai, India). A $50 \mu \mathrm{L}$ portion of samples of four different concentrations were filled in four wells (i.e., 0.25 to $1 \mu \mathrm{g}$ ) and DMSO act as a negative control. The dishes were then incubated for $24 \mathrm{~h}$, at $37{ }^{\circ} \mathrm{C}$ (Eppendorf, Innova 42). On completion of incubation, areas of inhibition formed around the wells were measured by a transparent ruler (geometric) in millimeters. The antimicrobial activity of the sample was measured by applying following formula; ZIO = diameter of total inhibition $(\mathrm{mm})-$ diameter of the well (mm).

Turbidity assay. This assay was performed, in order to evaluate the Minimum Inhibitory Concentration (MIC) and Minimum Bactericidal Concentrations (MBC) of the SBT@AgNPs. In detail, $5 \mathrm{~mL}$ glass vial $(5 \mathrm{~cm} \times 1.5 \mathrm{~cm})$ containing $4 \mathrm{~mL}$ BHI-broth inoculated with $\sim 10^{5} \mathrm{CFU} \mathrm{mL}^{-1}$ of bacteria. Then, different concentration of SBT@AgNPs (i.e., 2 to $6 \mu \mathrm{g} \mathrm{mL}{ }^{-1}$ ) was added and mixed gently. Then, the solution incubated in a shaking incubator (Eppendorf, Innova 42) at $37{ }^{\circ} \mathrm{C}$ for $24 \mathrm{~h}$. After the incubation, the progress of inhibition was observed on the vials, where the minimum concentration that did not have any turbidity was taken as MIC (Minimum Inhibitory Concentration) value of SBT@AgNPs. Moreover, $2 \mathrm{~mL}$ of solution transferred to other round-bottom glass vial and taking photos with a digital camera (Canon). To quantitatively determine the antibacterial activity of the SBT@AgNPs being properly diluted, (serial dilution) $100 \mu \mathrm{L}$ bacterial suspension were speared onto the Brain-heart infusion agar plates (BHI-A). The plates were then incubated at $37^{\circ} \mathrm{C}$ for $24 \mathrm{~h}$. Photographs of Salmonella typhimurium and Salmonella enterica grown on BHI-A plates were obtained and a number of colonies were counted manually and calculated the antibacterial activity of SBT@AgNPs. The lower most concentration was taken for bacteriological progress on the BHI-A plates and selected for MBC (Minimum Bactericidal Concentrations).

Live and dead assay. The live/dead assay was employed to evaluate the effect of SBT@AgNPs on the bacterial cell membrane integrity. ${ }^{37} 6 \mu \mathrm{g} \mathrm{mL}^{-1}$ of SBT@AgNPs were added into $\sim 10^{5} \mathrm{CFU} \mathrm{mL}{ }^{-1}$ bacterial cells, the mixture was incubated at $37^{\circ} \mathrm{C}$ for $24 \mathrm{~h}$. Then the solution was centrifuged the collected bacteria were resuspended in $1 \mathrm{~mL} \mathrm{LB}$ medium and then incubated with $10 \mu \mathrm{L} \mathrm{AO} / \mathrm{PI}$ at $37^{\circ} \mathrm{C}$ for $10 \mathrm{~min}\left(5 \mathrm{mg} \mathrm{mL}{ }^{-1}\right.$ and $3 \mathrm{mg} \mathrm{mL}^{-1}$ ). Subsequently, the bacterial suspension was centrifuged at $5000 \mathrm{~g}$ for 7 minutes at $4{ }^{\circ} \mathrm{C}$, and the supernatant was discarded. The unincorporated dyes were removed by washing (4 times) with phosphate-buffered saline (PBS). One droplet of cell suspension $(5 \mu \mathrm{L})$ was dropped on the freshly treated glass slide, and then it was covered with the coverslip without any air bubbles. The cells were microphotographed with the magnification of $40 \times$ using a confocal laser scanning microscope (Carl Zeiss LSM 510).

\section{Preparation of SBT@AgNPs sheet}

In order to prepare the SBT@AgNPs sheet, we immersed Whatman No. 1 paper in $10 \mathrm{~mL}$ of silver nitrate solution (1000 ppm) for 30 minutes. Then we removed the paper from silver nitrate solution and rinsed with water (Milli-Q) for several times to remove the excess silver nitrate that was not absorbed into the Whatman No. 1 paper. To form SBT@AgNPs, the paper was placed in an aqueous solution of SBT $\left(2 \mu \mathrm{g} \mathrm{mL}{ }^{-1}\right)$ for 20 minutes. Following this, the paper was removed from the solution and washed with water (Milli-Q) to remove the excess aqueous solution of SBT, and the excess water from the paper removed by drying the paper in a hot air oven at $50{ }^{\circ} \mathrm{C}$ for $2 \mathrm{~h}$. The paper was measured via scanning electron microscopy (SEM) before and after preparation SBT@AgNPs on the paper sheet.

\section{Evaluation of antibacterial activity of SBT@AgNPs sheet and comparison with medicated dressing materials}

To evaluate the antibacterial activity of the SBT@AgNPs sheet was investigated against bacterial cocktails (Escherichia coli, 
Salmonella typhimurium, Salmonella enteric, Pseudomonas aeruginosa and Bacillus subtilis). We selected these bacterial organisms because of their role in primary causes of delayed healing and infection in both acute and chronic wounds and contamination in drinking water. At the onset, for bacterial cell preparation, we inoculated single colony of bacteria in five different conical flasks contacting $25 \mathrm{~mL}$ nutrient broth and incubated at $37^{\circ} \mathrm{C}$ for $24 \mathrm{~h}$. Thereafter, cells were harvested by centrifugation (6000 rpm for $10 \mathrm{~min}$ ) and washed three times with phosphate buffer (10 mM, pH 7.2). The cell pellets were finally resuspended in the same phosphate buffer to obtain the cell density of $0.1 \mathrm{OD}$ at $600 \mathrm{~nm}$ (Optical density) approximately $10^{5} \mathrm{CFU} \mathrm{mL}^{-1}$, the same procedure was followed for all bacterial suspension preparation. Moreover, in $5 \mathrm{~mL}$ vial each bacterial suspension was pooled $(1: 1)$. Then, $100 \mu \mathrm{L}$ of the mixed bacterial suspension was spread uniformly on nutrient agar plates $(9.0 \mathrm{~cm} \times 9.0 \mathrm{~cm})$ and the SBT@AgNPs sheet $(25 \mathrm{~mm} \times$ $15 \mathrm{~mm})$ were placed using sterile forceps and plates were incubated at $37{ }^{\circ} \mathrm{C}$ for $24 \mathrm{~h}$. On completion of incubation, the zone of growth inhibition was measured by a transparent ruler (geometric) in millimeters, and all the test were repeated three times. The width of zone growth inhibition was calculated following equation: $W(\mathrm{~mm}): T-D$. Where ' $W$ ' is the width of inhibition zone, $T$ is the total diameter of the paper and inhibition zone, and $D$ is the diameter of the SBT@AgNPs sheet respectively. In order to compare the antibacterial activity of SBT@AgNPs sheet with medicated dressing materials, we procured commercially available medicated dressing materials from medical shop, Chandigarh, India. The same procedure was followed described earlier and the results were compared with an inhibition zone of SBT@AgNPs sheet with medicated dressing materials.

\section{Routine infection-control measures and environmental decontamination using SBT@AgNPs}

Nanomaterials can be used as disinfectants due to their antimicrobial properties and reduce the possibility of harmful disinfection, this motivates us to evaluate the efficiency of our synthesized SBT@AgNPs as disinfected in the day to day life. At the onset, the bacterial cocktails (Escherichia coli, Salmonella typhimurium, Salmonella enterica, Pseudomonas aeruginosa and Bacillus subtilis) used for this study. The same protocol was used for the preparation of bacterial suspension described earlier. Then, in $250 \mathrm{~mL}$ conical flask we prepared $200 \mathrm{~mL}$ mixed bacterial suspension $(1: 1)$ and in our laboratory surface $\left(232^{\prime} \times\right.$ $232^{\prime}$ ) spread uniformly using sterile wiper and left for drying 10 to 15 minutes. Moreover, $25 \mathrm{~mL}$ SBT@AgNPs $\left(6 \mu \mathrm{g} \mathrm{mL} \mathrm{m}^{-1}\right)$ was uniformly spread by using sterile wiper and as control, sterile water $(25 \mathrm{~mL})$ used on the surface. Then, the sample was collected (i.e. $0,0.5$ and $1 \mathrm{~h}$ ) five random place using sterile wood cotton swabs and transfer into $5 \mathrm{~mL}$ sterile water stored at $4{ }^{\circ} \mathrm{C}$. On completion of sample collection the swabs are pooled $0,0.5$ and $1 \mathrm{~h}$ respectively, and transfer into the $20 \mathrm{~mL}$ nutrient broth. Then, the solution incubated in a shaking incubator (Eppendorf, Innova 42 ) at $37{ }^{\circ} \mathrm{C}$ for $24 \mathrm{~h}$. After the incubation, the progress of inhibition was observed on the glass vials, to quantitatively determine the antibacterial activity of the SBT@AgNPs being properly diluted, (serial dilution) $100 \mu \mathrm{L}$ bacterial suspension were speared onto the nutrient agar plates (NA). The plates were then incubated at $37^{\circ} \mathrm{C}$ for $24 \mathrm{~h}$. Photographs of bacteria grown on NA plates were obtained and a number of colonies were counted manually and calculated the antibacterial efficiency (routine infection-control measures and environmental decontamination) of SBT@AgNPs.

\section{Antioxidant evaluation with DPPH free radical scavenging} assay

The free radical scavenging action of SBT@AgNPs was estimated using the method described by Garry et al. ${ }^{38}$ with slight modification. DPPH assay was performed in 96 wells plates (Nunc, Thermo Scientific, Denmark). Then, different concentration of (i.e. 2 to $20 \mu \mathrm{g}) 20 \mu \mathrm{L}$ SBT@AgNPs solution was poured in respective wells of the plates and then $180 \mu \mathrm{L}$ of DPPH solution was added in each well the final volume of the reaction $200 \mu \mathrm{L}$ and ascorbic acids used as reference standard. The mixture was incubated at $37{ }^{\circ} \mathrm{C}$ for 30 minutes. The color change was observed from violet to yellow due to the antioxidation potential. The absorbance of the reaction mixture was measured at $517 \mathrm{~nm}$ on a microplate reader (Spectramax i3x, Molecular Devices, CA, USA). Scavenging activity was calculated the following equation.

$\%$ scavenging $=\frac{\mathrm{OD} \text { of control }-\mathrm{OD} \text { of test sample }}{\mathrm{OD} \text { of control }} \times 100$

\section{A stability and longevity study of SBT@AgNPs}

To examine the stability of SBT@AgNPs, we evaluated the morphological changes of SBT@AgNPs before and after the storage. After the synthesis of SBT@AgNPs, $50 \mathrm{~mL}$ of NPs transfer into amber polypropylene bottles (Tarsons Products Pvt. Ltd. Kolkata, India), covered with aluminum foil and stored in the dark room (away from light) for one year. Periodical visible observation and UV-absorbance measurements of the NP solutions were carried out during the storage period. After one year of storage UV-absorbance measurements was carried out (without dilution), then $2 \mathrm{~mL}$ of NPs transfer into glass vial then sonicated for 15 minutes at $27^{\circ} \mathrm{C}$, and then HRTEM, dynamic light scattering, and zeta potential $(\zeta)$ analysis were performed. To investigate the antibacterial efficiency of SBT@AgNPs upon storage, approximately $20 \mathrm{~mL}$ of SBT@AgNPs was centrifuged at $10000 \mathrm{rpm}$ for 20 minutes and washed thrice with distilled water. The precipitate was desiccated at $50^{\circ} \mathrm{C} 24 \mathrm{~h}$ and used for antibacterial activity as per protocol described earlier.

\section{Results and discussions}

\section{Synthesis of SBT@AgNPs}

Sustainable and green preparation of SBT@AgNPs was carried out by Seabuckthorn (SBT) aqueous leaves extracts mediated reaction of silver iron $\left(\mathrm{Ag}^{+}\right)$into silver NPs $\left(\mathrm{Ag}^{0}\right)$ without using any chemicals. SBT@AgNPs was synthesized in addition of 
dried SBT leaves powder to silver nitrate solution resulted in a gradual color change was noted by naked eye from harry light yellow, light yellow, fancy yellow and finally to brown color due to the formation of SBT@AgNPs. The color change occurs because of the excitation of surface plasmon vibrations of the AgNPs. ${ }^{39}$ Onset, for the formation of SBT@AgNPs, was studied with different concentrations (i.e. 0.5 to $2.0 \mathrm{mg}$ ) of dried SBT leaves powder with a $1000 \mathrm{ppm} \mathrm{AgNO}_{3}$ solution. The UV-vis spectra Fig. 1a shown the formation of SBT@AgNPs using different concentrations of dried SBT leaves powder at room temperature for a time span of 60 minutes, and $2 \mathrm{mg}$ dried SBT leaves powder yielded the best result exhibiting highly stable and the highest SPR band at $430 \mathrm{~nm}$. Furthermore, we studied the UV-vis absorbance of the reaction mixture with $2 \mathrm{mg}$ dried SBT leaves powder with varying the time intervals (i.e. $0,0.5,1$, $2,4,6,12,24,48 \mathrm{~h})$. It was observed that formation of SBT@AgNPs started within 2 minutes and reached at an optimum level within 20 minutes (SPR at $430 \mathrm{~nm}$ ). Although most of the SBT@AgNPs formation was accomplished within $1 \mathrm{~h}$, the reaction mixture was kept at the room temperature for $24 \mathrm{~h}$ to ensure the completion of the reaction; the completion of the reaction was proved by the negligible increase of the maximum absorption bands of the NPs Fig. 1b. In UV-vis spectra Fig. 1c the absorbance peak at $230 \mathrm{~nm}, 240 \mathrm{~nm}$, $250 \mathrm{~nm}$ and 260 wavelengths as shown in the leaf extract indicates the presence of phenol compounds. ${ }^{\mathbf{4 0 , 4 1}}$ Formation of SBT@AgNPs may owe the presence of polyphenols complex present in the SBT leaf extracts that induce the reduction of $\mathrm{Ag}^{+}$ into AgNPs $\left(\mathrm{Ag}^{0}\right)$. Moreover, the absorbance peak at $430 \mathrm{~nm}$ confirmed the formation of SBT@AgNPs and also observed the peak at $260 \mathrm{~nm}$ and $270 \mathrm{~nm}$ due to the capping of oxidized polyphenols; which enhance the stabilization of SBT@AgNPs, ${ }^{\mathbf{4 0}}$ the same further confirmed by FTIR.

\section{Characterizations of SBT@AgNPs (TEM, EDX, and zeta)}

The TEM micrographs of the synthesized SBT@AgNPs nanocomposite were represented by Fig. 2a. The TEM pattern clearly depicted the formation of SBT@AgNPs are mostly spherical structure.SBT@AgNPs nanoparticles having an average particle diameter of $\sim 10-40 \mathrm{~nm}$. Furthermore, the TEM EDX analysis clearly shows the presence of silver in Fig. 2b, the particle morphology observed from the TEM analysis supports our UVvis absorption band at $430 \mathrm{~nm} .{ }^{\mathbf{4 2}}$ further, we analyzed to see the capping effect of natural molecules on the particle surface

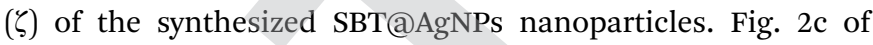
shows the $\zeta$ potentials of as-synthesized, SBT@AgNPs with negative $\zeta$ potential value $-29 \pm 0.11 \mathrm{mV}$. These may owe to biomolecules bind to the surface of SBT@AgNPs and significantly increase their surface charge that enhances their stability by inhibiting aggregation. ${ }^{40,43}$ The results corroborate that leaf extract mediated NPs have smaller size and large surface with less aggregation that may enhance the antibacterial activity. ${ }^{\mathbf{4 4 , 4 5}}$

\section{FTIR analysis}

FTIR analysis was employed to identify the potential functional groups responsible for the bio-reduction of the metal precursors and the stabilization of the NPs. In SBT leaves extract peaks were observed at 3456, 2352, 1450, 1425, 1285, and $1065 \mathrm{~cm}^{-1}$ before the reduction Fig. 2d. In general, the peaks at 1065 and

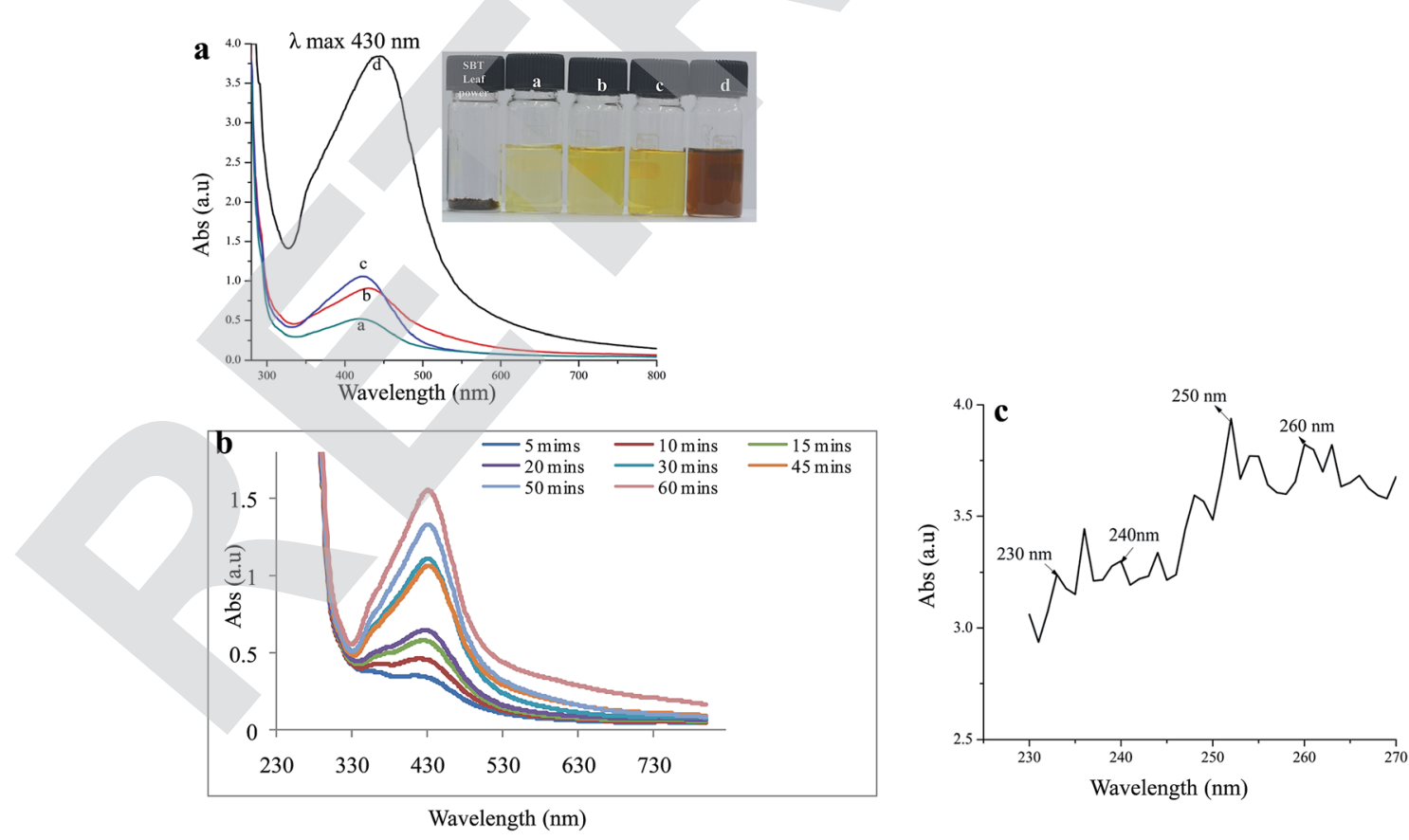

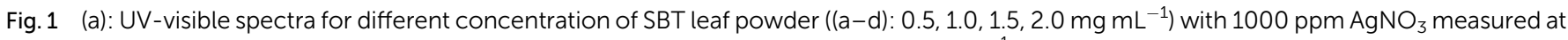
$60 \mathrm{~min}$. Along with respective vial showing change in colour (b) UV-vis spectra for $2 \mathrm{mg} \mathrm{mL}^{-1} \mathrm{SBT}_{\text {leaf powder with } 1000 \mathrm{ppm} \mathrm{AgNO}}$ at different time intervals. (c) UV spectra for leaf extracts speak shown at $230 \mathrm{~nm}, 240 \mathrm{~nm}, 250 \mathrm{~nm}$ and 260 wavelengths indicates the presence of phenol compounds. 

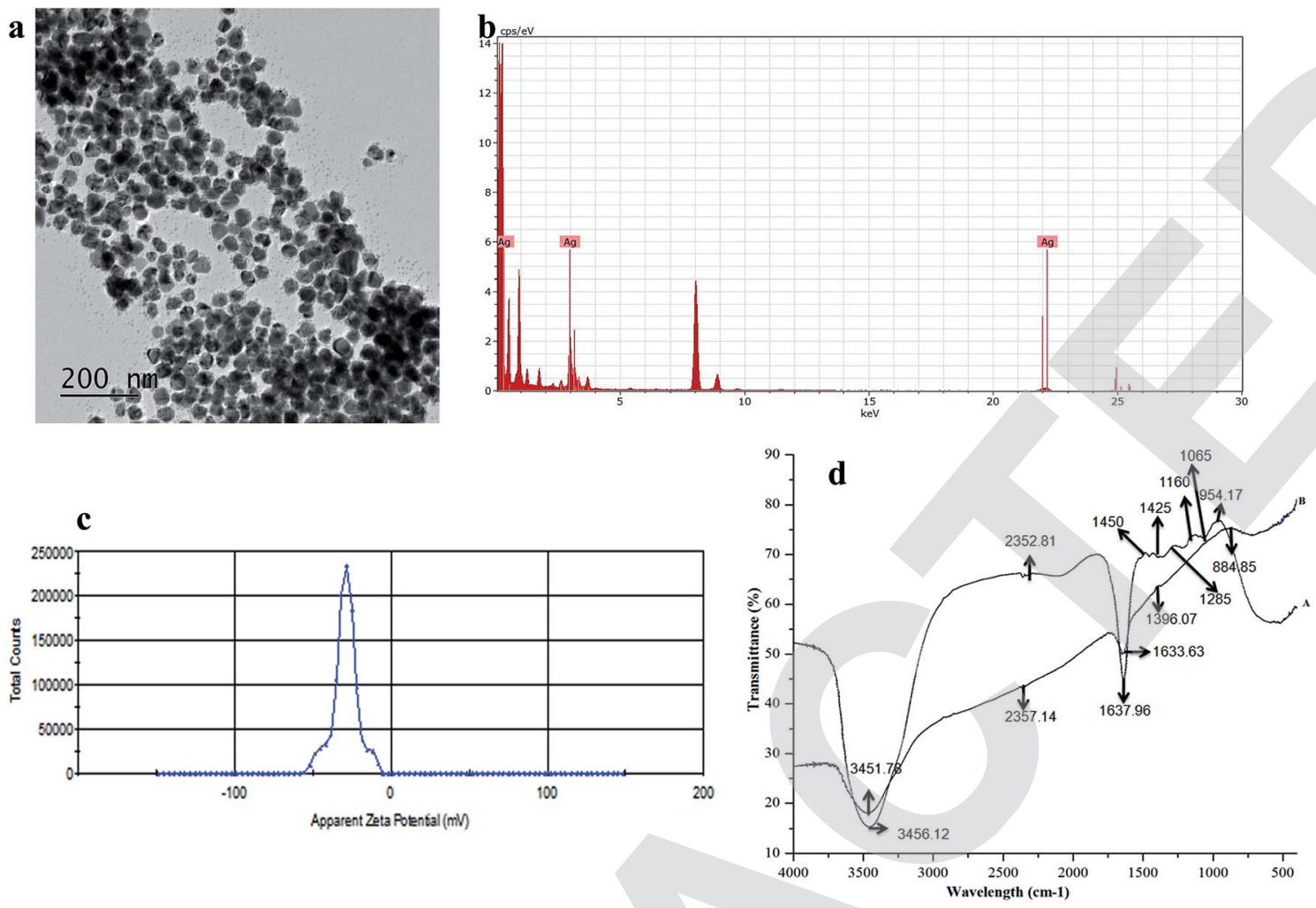

Fig. 2 (a) TEM of the synthesized SBT@AgNPs at room temperature $\left(25.0 \pm 2.0^{\circ} \mathrm{C}\right)$, (b) EDAX spectra of the synthesized SBT@AgNPs, (c) zeta

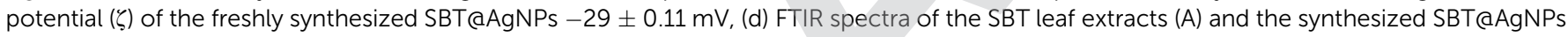
(B).

$1285 \mathrm{~cm}^{-1}$ are attributed to the hydroxyl in carbohydrate and the $\mathrm{C}-\mathrm{O}$ stretching vibration in cyclic compounds, respectively. ${ }^{40}$ The peaks at 2352 and $1450 \mathrm{~cm}^{-1}$ may be ascribed to the bending vibration and stretching vibration of $\mathrm{C}-\mathrm{H}$ in alkanes. The peak at $1637 \mathrm{~cm}^{-1}$ was referred to $(\mathrm{NH}) \mathrm{C}=\mathrm{O}$ and the peaks at $3451 \mathrm{~cm}^{-1}$ were assigned to the $\mathrm{O}-\mathrm{H}$ stretching vibration in alcohols and phenolic compounds respectively. ${ }^{40}$ Therefore, we concluded that the potential biomolecules in the SBT leave extract may contain a mixture of saccharides, polyphenols, protein, and carbonyl compounds. ${ }^{36}$ The FTIR spectra of SBT leaves extract after reacting with $\mathrm{AgNO}_{3}$ for $24 \mathrm{~h}$ at room temperature shown Fig. 2d, in comparison between Fig. 2d(A) and (B) revealed that the intensity of peaks at 1637, 2352, $3456 \mathrm{~cm}^{-1}$ decreased after the reaction, which evidenced that the reaction involved several compounds such as carbohydrate, cyclic, and alkanes present in the SBT leaves extracts. In addition, the peak at $1633 \mathrm{~cm}^{-1}$ in Fig. $2 \mathrm{~d}$ shifted to $1637 \mathrm{~cm}^{-1}$ and peaks at $1065,1425,1450,1285$ extract residues left after the reaction as well as in the as-formed SBT@AgNPs, result was attributed to the binding of the $\mathrm{C}-\mathrm{O}, \mathrm{C}-\mathrm{H}$ and $(\mathrm{NH}) \mathrm{CO}$ groups with the as-synthesized SBT@AgNPs. Moreover, a new peak at $1396 \mathrm{~cm}^{-1}$ appeared, which could owe to the $\mathrm{C}=\mathrm{O}$ stretching vibration in carbonyl compounds. On the basis of the FTIR analysis, we speculate that $\mathrm{C}-\mathrm{O}, \mathrm{O}-\mathrm{H}$, and $\mathrm{C}-\mathrm{O}$ compounds are responsible for the reduction of metal precursors $\left(\mathrm{Ag}^{+}\right)$, and the bio-compounds with the $(\mathrm{NH}) \mathrm{C}=\mathrm{O}$ groups related to the stabilization of the SBT@AgNPs.

\section{Antibacterial activity of the biosynthesized SBT@AgNPs}

The emergence of Salmonella strains resistant to first-lineantibiotics as well as increased MICs, is tending to be a serious problem limiting the possibility for effective treatment of human and animal Salmonella infection. ${ }^{46}$ The AgNPs were widely being known for their effective antimicrobial for a wide spectrum of bacteria. In this work, we employed the antibacterial efficiency of biosynthesized SBT@AgNPs nanoparticles in the context of its dose-dependent effect on the bacterial growth. The antibacterial activity of SBT@AgNPs was examined two Salmonella strains namely against Salmonella typhimurium, Salmonella enterica by a zone of inhibition (ZOI) and colony forming unit (CFU). The ZOI results shown in Fig. 3a, it is observed that the ZOI was directly proportional to the concentration of SBT@AgNPs. The effective inhibition observed in our studies was in the range of 18 to $33 \mathrm{~mm}$ for 0.25 and $1 \mu \mathrm{g} \mathrm{mL} L^{-1}$, respectively. This antibacterial efficacy is much higher than already reporting values. ${ }^{47,48}$ This finding demonstrating that remarkably high antibacterial activity against test microbial organisms. To quantitatively determine the antibacterial activity of the SBT@AgNPs was performed by colony forming unit (CFU), the Salmonella strains were incubated for $12 \mathrm{~h}$ at different concentration (i.e., 2 to $6 \mu \mathrm{g} \mathrm{mL}{ }^{-1}$ ) of SBT@AgNPs Fig. 3b. Subsequently, the bacterial cells were grown in the BHI plates. The number of colonies on BHI plates was analyzed and surviving colonies were calculated after $24 \mathrm{~h}$ of incubation. The 


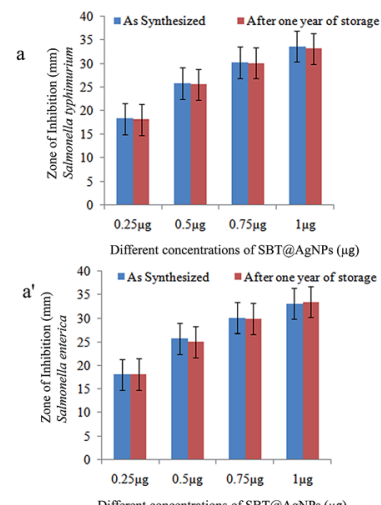

Different concentrations of $\mathrm{SBT} @ \mathrm{Ag} \mathrm{NPs}(\mu \mathrm{g})$
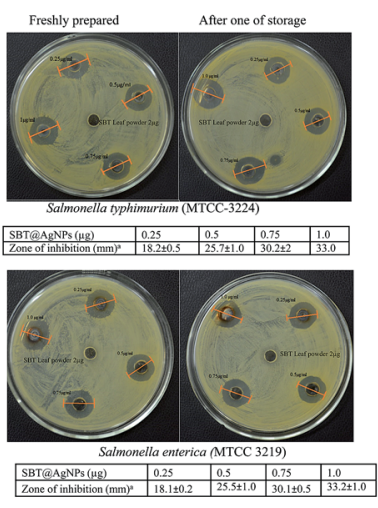

*values are mean $t$ s.d. (n $h=4$

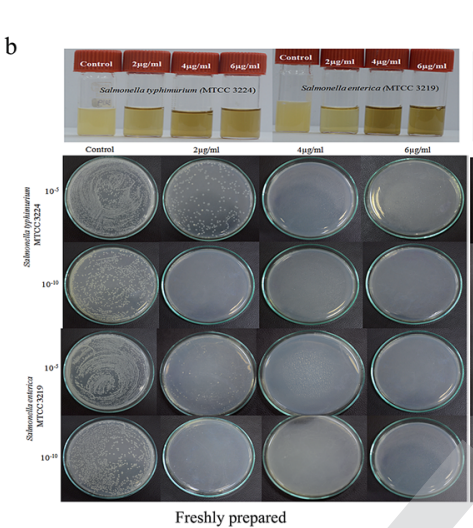

$b^{\prime}$

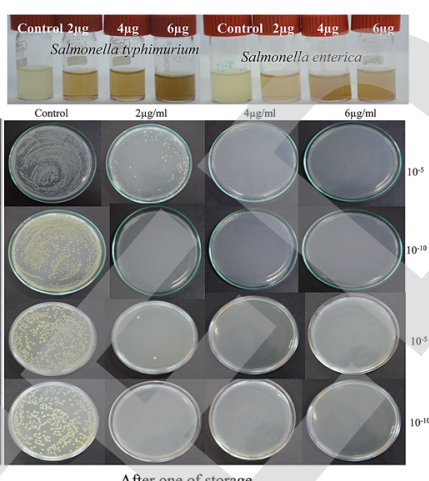

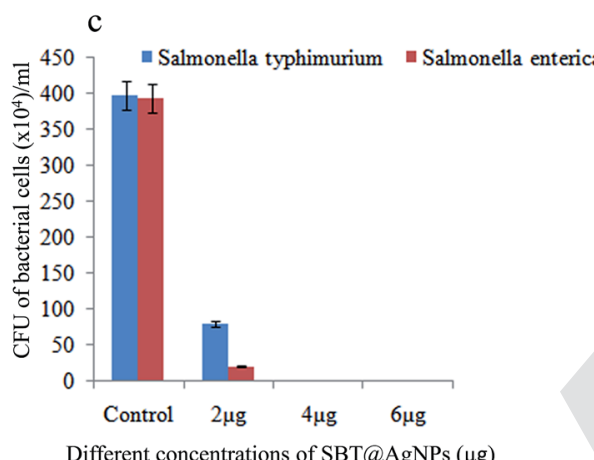

Different concentrations of SBT@AgNPs $(\mu \mathrm{g})$

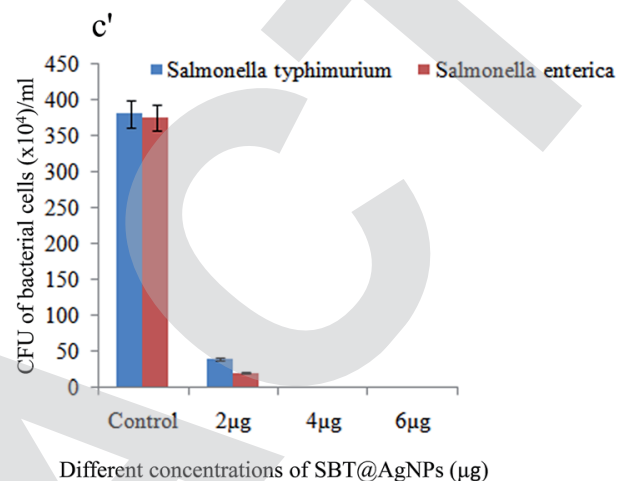

Fig. $3\left(a, a^{\prime}\right)$ Histograms along with Petri disk image showing antibacterial activity (ZOI) of SBT@AgNPs against salmonella Sps (0.25, 0.5, 0.75, 1.0 $\mu \mathrm{g})$ freshly prepared and after one of storage, $\left(b, b^{\prime}\right)$ vial image showing turbidity assay towards salmonella Sps and Petri plate image showing colonies of salmonella Sps incubated on BHI agar obtained from cultivated suspension with SBT@AgNPs. (c, c') Quantitative evaluation of the antimicrobial ability of freshly prepared and after one year stored SBT@AgNPs by counting the colonies (CFU) grown on BHI agar plates. The

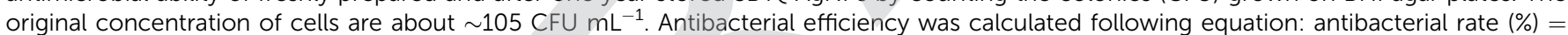
$\left(N_{\text {control }}-N_{\text {sample }}\right) / N_{\text {control }} \times 100$ mean values and standard deviation are calculated from four independent experiments.

SBT@AgNPs inhibited the growth of Salmonella typhimurium, Salmonella enterica in a dose-dependent manner Fig. 3c. The results are shown at the concentration $4 \mu \mathrm{g}$ there is no growth observed in both Salmonella strains even after $48 \mathrm{~h}$ of culture. However, we compared our results with already reported value for the same organism.. ${ }^{49,50}$ Data revealed that SBT@AgNPs higher antibacterial activity at the lowest concentration $(4 \mu \mathrm{g})$. The Table 1 is shows the comparisons studies of MIC and time duration of the reaction of our prepared SBT@AgNPs with already reported studies. The table is clearly indicates that our prepared SBT@AgNPs have very good antibacterial activity at lowest concentration and highly stable NPs as compared to reported elsewhere. In fact, this study showed SBT@AgNPs nanoparticles more activity against the two Salmonella strains. The outcomes of the present work reveal that the biosynthesized SBT@AgNPs nanoparticles have an excellent

Table 1 Comparison of MIC and rate of reaction for synthesized SBTaAgNPs with other phytosynthesis of AgNPs

\begin{tabular}{|c|c|c|c|c|c|}
\hline Plant sources & Concentration $^{a}$ & Reaction time (h) & Size (nm) & MIC $(\mu \mathrm{g})$ & Reference \\
\hline Z. mays L. (ear leaves) & $20 \%$ & $24 \mathrm{~h}$ & $\sim 60$ & 50 & 51 \\
\hline Chamaemelum nobile (whole plant) & $2.5 \%$ & $24 \mathrm{~h}$ & $\sim 47.3$ & 7.8 & 52 \\
\hline Phlomis (leaves) & $16 \%$ & $0.5 \mathrm{~h}$ & $\sim 25$ & 100 & 54 \\
\hline Seabuckthorn (leaves) & $0.02 \%$ & $1 \mathrm{~h}$ & $\sim 10-40 \mathrm{~nm}$ & 2 & Present study \\
\hline Azadirachta indica (leaves) & $20 \%$ & $24 \mathrm{~h}$ & $\sim 34$ & 12 & 55 \\
\hline
\end{tabular}

${ }^{a}$ Following formula used for calculate the \% reducing agents (leaf materials), $X$ gram of leaves extracts mixed with $100 \mathrm{~mL}$ water in that $X$ amount of volume used for the preparation of NPs. Example: $20 \mathrm{~g}$ leaves extract mixed in $100 \mathrm{~mL}$ water and boiled for the preparation of leaves extract, in that some amount used for the preparation of NPs. So, we assumed $20 \%$ leaves extract used. In our case used dried powder for NPs preparation $2 \mathrm{mg} / 100$. (i.e. $0.02 \%)$. 


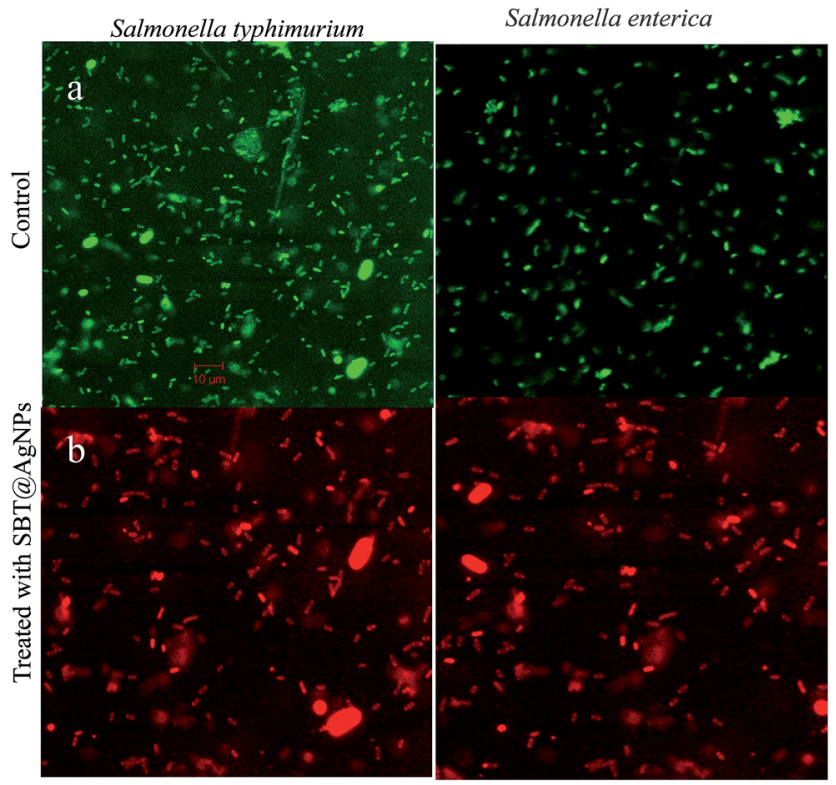

Fig. 4 Confocal images of Salmonella Sps before and after treated with SBT (aAgNPs $\left(6 \mu \mathrm{g} \mathrm{mL}^{-1}\right)$ for $2.5 \mathrm{~h}$ and stained with acridine orange (green, indicator of intact membrane, live cells) and propidium iodide (red, indicator of membrane damage, dead). (Scale bar $10 \mu \mathrm{m}$ ).

antibacterial property which can able to serve as a good bactericidal agent.

\section{Disturbance of bacterial cell membrane by SBT@AgNPs}

To investigate the relationship between SBT@AgNPs and bacterial cell membrane damage, Salmonella cells, after being treated $\left(6 \mu \mathrm{g} \mathrm{mL} \mathrm{m}^{-1}\right)$ with NPs and stained with acridine orange (AO), propidium iodide (PI), were observed under confocal fluorescence microscopy. The green fluorescent (AO) stain only alive cells and propidium iodide (PI) stain only dead cells which used for visual differentiation between live and dead cells based on membrane integrity. ${ }^{37}$ The figure represents the distribution of dead/viable bacteria, wherein Fig. 4a, only live bacteria appear in green fluorescence which is corresponding to the control untreated bacteria. Fig. $4 \mathrm{~b}$ represents the $6 \mu \mathrm{g} \mathrm{mL}{ }^{-1}$ SBT@AgNPs treatment, the viability was zero only red fluorescence appeared as a result of dead abundance. These results suggest that the treatment of Salmonella strain with the SBT@AgNPs leads to cell death and/or bacteriostatic effect. ${ }^{37}$

\section{Preparation and characterization of SBT@AgNPs sheet}

The SBT@AgNPs was readily formed by the in situ reduction of silver nitrate solution absorbed in the paper. The sheets changed color from white to brown after reaction with silver nitrate Fig. 5a and b. The color changes are due to the surface plasmon resonance of AgNPs. ${ }^{56}$ Next, we examined the paper before and after coating with SBT@AgNPs under SEM it observed that NPs fully stain paper fibers Fig. $5 \mathrm{c}$ and d. These results suggest that the NPs formed on the paper, further we studied antibacterial activity of SBT@AgNPs sheet.

\section{Antibacterial activity of SBT@AgNPs impregnated paper}

The SBT@AgNPs impregnated paper provided rapid and effective bactericidal activity against the model of bacterial cocktails (Escherichia coli, Salmonella typhimurium, Salmonella enterica, Pseudomonas aeruginosa and Bacillus subtilis). The antibacterial activities of SBT@AgNPs paper was examined by a zone of inhibition (ZOI). To evaluate this $100 \mu \mathrm{L}$ of bacterial cocktails $\left(10^{5} \mathrm{CFU} \mathrm{mL}{ }^{-1}\right)$ spread on the NA plate (nutrient agar) and placed SBT@AgNPs sheet $(25 \mathrm{~mm} \times 15 \mathrm{~mm})$ were placed using sterile forceps and plates were incubated at $37^{\circ} \mathrm{C}$ for $24 \mathrm{~h}$. On completion of incubation, the zone of growth inhibition

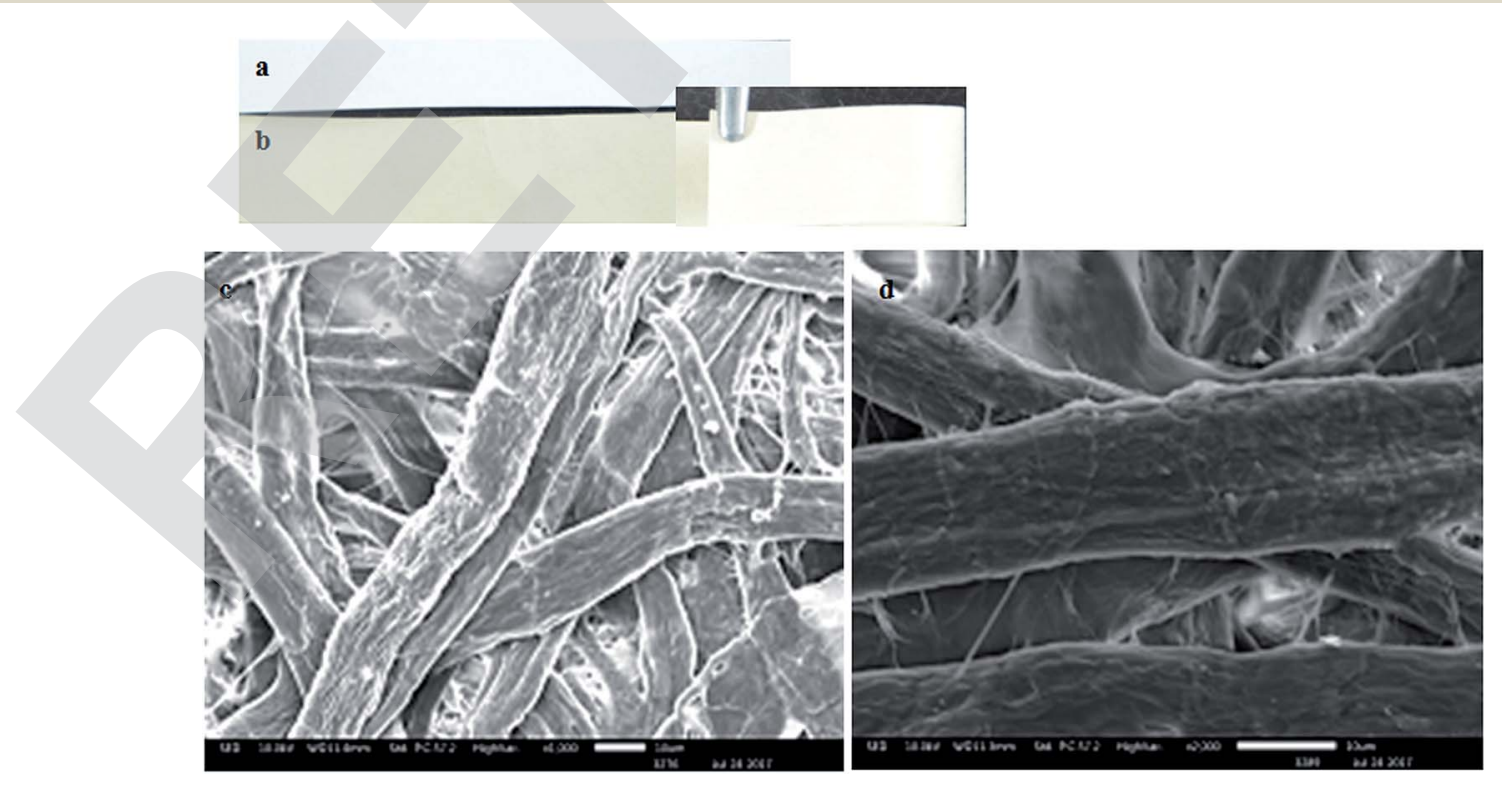

Fig. 5 Characterization of SBT@AgNPs impregnated paper, image before impregnated (a), after impregnated (b), SEM image of paper before impregnation (c) and after impregnated (d). 
observed around the plate the ZOI results in Fig. 6a. Moreover, we compared our results (ZOI) with commercially available two medicated dressing materials the same size $(25 \mathrm{~mm} \times 15 \mathrm{~mm})$ against bacterial cocktails $\left(\sim 10^{5} \mathrm{CFU} \mathrm{mL} \mathrm{m}^{-1}\right)$, it was observed that did not show any ZOI after incubation with $24 \mathrm{~h}$. To investigate the deterioration and longevity of SBT@AgNPs sheet after being stored at room temperature, we studied the antibacterial efficiency of the paper different at time intervals (i.e., freshly, 6 and 12 months). We observed that insignificant change in the ZOI (Fig. 6b). The SBT@AgNPs prepared by the in situ reduction method, this is due to the good adherence of AgNPs to paper. The antibacterial activity of paper, presumably due to the $\mathrm{Ag}^{+}$release from the AgNPs formed on the paper. It is significance that a very recent study showed that bacteria did not grown on the paper composed of a tween/rGO composite ${ }^{57}$ and graphene oxide (GO), reduced graphene oxide (rGO) nanosheet, ${ }^{58}$ rather than the Seabuckthorn silver nanoparticles based bacterial killing not yet reported. Therefore, these results demonstrated that the biosynthesized SBT@AgNPs impregnated paper can contribute to increasing the workability and efficiency of antibacterial dressing materials.

\section{Routine infection-control measures and environmental decontamination using SBT@AgNPs in the day to day life}

The role of the environment in harboring and transmitting multidrug-resistant organisms has become clearer due to a series environmental contamination with an increased risk of hospital-associated infections. The occurrence of antimicrobial

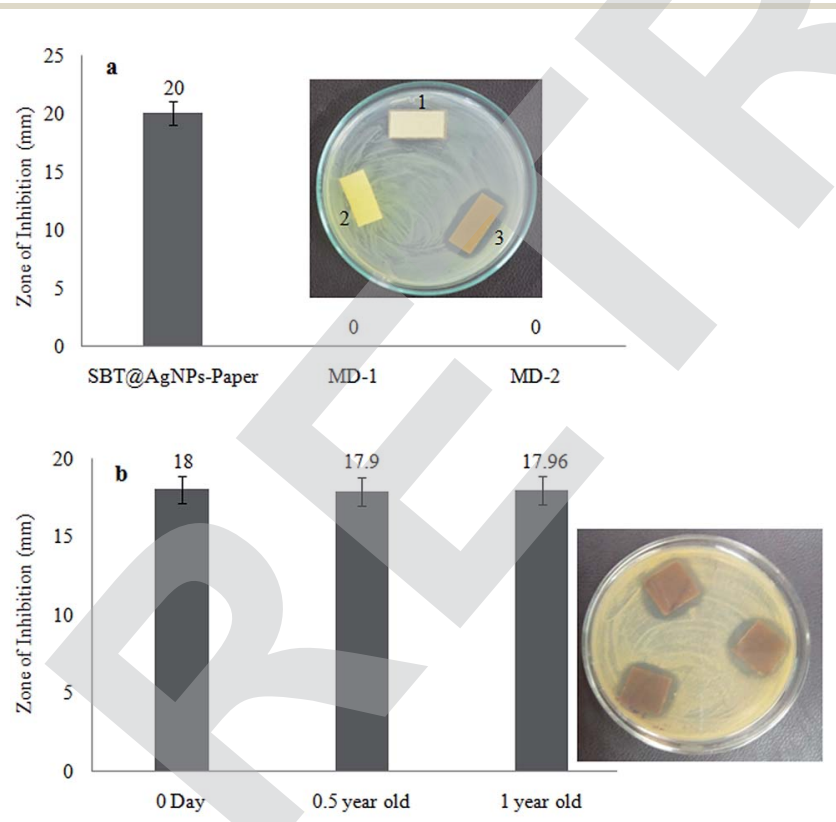

Fig. 6 (a) Antibacterial activity (zone of inhibition, ZOI) of SBT@AgNPs impregnated paper with comparison to commercially available medicated dressing materials (MD-1,2). Inserted Petri disk image showing ZOI of 1. MD-1, 2. MD-2, 3. SBT@AgNPs impregnated paper, (b) antibacterial activity (zone of inhibition, ZOI) of SBTaAgNPs impregnated paper. (1) Freshly prepared (2) after 6 months (3) after one year. Mean values and standard deviation are calculated from four independent experiments. resistance is also increasing, leading to higher morbidity and mortality associated with hospital-associated infections. With this background, we investigated our biosynthesized SBT@AgNPs possibility way to implement from the lab day to day usage as disinfectants. According to the Asia Pacific Society of Infection Control (APSIC) components of the cleaning process (disinfects/ chemical) the observation of colony forming units (CFU) before and after treatment. In our study, we used bacterial cocktails (Escherichia coli, Salmonella typhimurium, Salmonella enterica, Pseudomonas aeruginosa and Bacillus subtilis) to contaminated $\left(10^{5} \mathrm{CFU} \mathrm{mL}{ }^{-1}\right)$ the laboratory surface $\left(232^{\prime} \times 232^{\prime}\right)$ and treated with SBT@AgNPs $\left(6 \mu \mathrm{g} \mathrm{mL}^{-1}\right)$. To evaluate the antibacterial efficiency of SBT@AgNPs sample was collected like 0, 0.5, 1.0 h and culture on LB broth for $24 \mathrm{~h}$ after the incubation it was observed that inhibition of bacterial growth against bacterial cocktails. To quantitatively determine the antibacterial activity of the SBT@AgNPs bacterial culture was serially diluted and plated on nutrient agar (NA) after $24 \mathrm{~h}$ of incubation it observed that the bacterial cells were grown in the NA plates Fig. 7a. In comparison with Fig. $7 \mathrm{~b}$ and no growth was an observed bacterial cocktail treated with $6 \mu \mathrm{g} \mathrm{mL} \mathrm{m}^{-1}$ after $0.5 \mathrm{~h}$, and there was growth observed less then untreated (control) in $0 \mathrm{~h}$. In fact, in this study, SBT@AgNPs nanocomposite showed more activity against bacterial cocktails. The outcomes of the current work unveil that the biosynthesized nanocomposites have an excellent antibacterial property which can able to serve as a bactericidal agent infection-control in the day to day life.

\section{DPPH free radical scavenging assay (antioxidant assay)}

The antioxidant potentials of SBT@AgNPs were investigated and compared to that of the plant extracts of SBT leaves extracts and ascorbic acid. The results are presented as a histogram in Fig. 8. The SBT@AgNPs exhibited good DPPH radical scavenging capacity. The results also reflected the dose dependence of the antioxidant properties of the samples as there was an increase in percentage DPPH radical scavenging abilities as their concentrations $\left(5-25 \mu \mathrm{g} \mathrm{mL}{ }^{-1}\right)$ increased. We used one way ANOVA for comparison of mean and significance at $0.05<p$

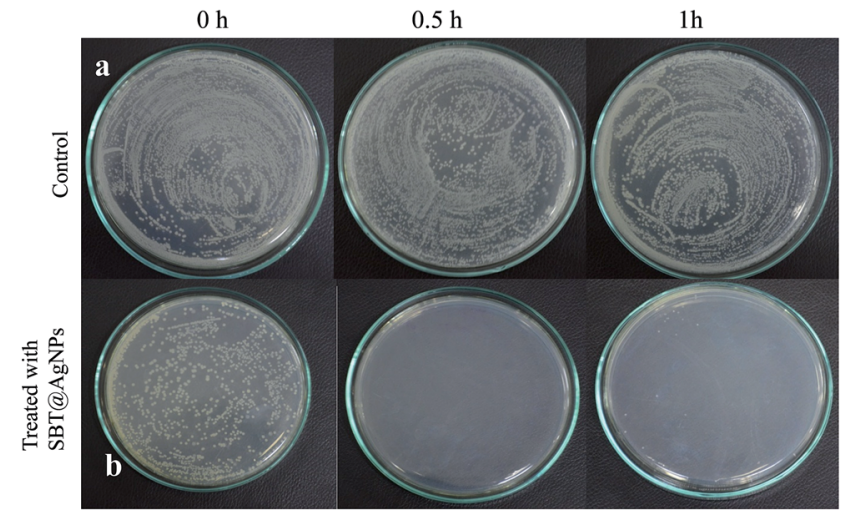

Fig. 7 The nutrient agar plat showing antibacterial activity against bacterial cocktail on routine infection-control measures and environmental decontamination using SBT (aAgNPs in the day-to-day life. (a) Untreated (control), (b) treated with 1 SBT@AgNPs $\left(6 \mu \mathrm{g} \mathrm{mL}^{-1}\right)$. 


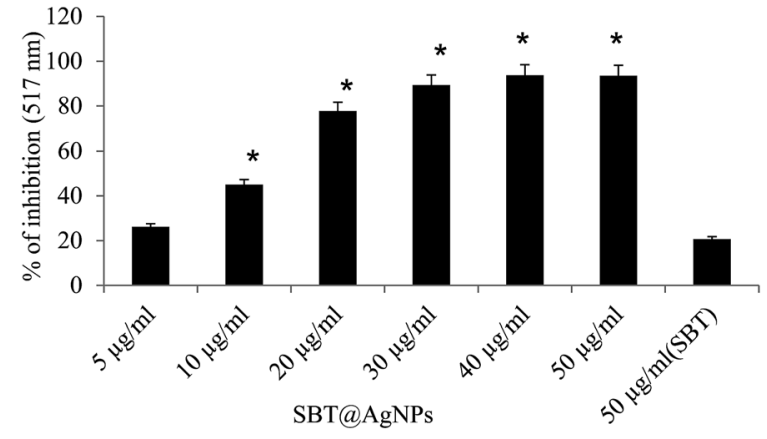

Fig. 8 Comparative study on DPPH radical scavenging activity of different concentration of SBTaAgNPs and SBT extract alone. *Histogram (mean $\pm \mathrm{SE}$ ) showing steric mark indicates significant change $(0.05<p)$ with comparison with SBT leaves extract alone.

with SBT leaves extract. We observed that silver nanoparticles have more than 10 fold increased DPPH radical scavengers compared to the plant extract. The enhanced antioxidant capacity of SBT@AgNPs can be attributed to the presence of some on the phytochemicals of SBT leaves extracts in the nanoparticles as capping agents. Some of which are flavonoids with several hydroxyl groups. The presence of these phytochemicals and silver ions could result to antioxidant activities proceeding through hydrogen atom transfer (HAT) and single electron transfer (SET) mechanisms simultaneously. ${ }^{37,38}$

\section{Stability and longevity study of SBT@AgNPs}

The long-term stability of SBT@AgNPs and storage effect was investigated by surface plasmon resonance observed from
UV-vis spectral analysis, morphology analysis by TEM and


The SPR data collected after one year of storage and compared with that of SBT@AgNPs synthesized. The SPR with $\lambda_{\max } 430$ remains nearly same indicative of unchanged $\lambda_{\max }$ (Fig. 9a) and TEM analysis was performed to characterize the effect of storage on the morphology of SBT@AgNPs. The TEM image offered that SBT@AgNPs is well-separated from each other and did not observe any change in the morphology and aggregation (Fig. 9b). Moreover, we investigated antibacterial efficiency upon the storage (Fig. $3 \mathrm{a}^{\prime}-\mathrm{c}^{\prime}$ ). The result indicated that insignificant change in the antibacterial activity as compared with freshly synthesized SBT@AgNPs. The results suggest that the phytochemical compounds present in the leaf extracts play a key role in providing stability to SBT@AgNPs. We assume that phytochemical compounds forming core structure and decreases surface potential that is responsible for the accumulation of the AgNPs leads to large aggregates. To understand this concept and to associate with long-term stability, we analyzed the surface charge of SBT@AgNPs. Since, dispersion with a low zeta potential value facilitates aggregation due to van der Waal inter-particle attractions. The outside zeta potential value range from $-25 \mathrm{mV}$ to $+25 \mathrm{mV}$ represent necessary electrical charge required for the high degree of NPs stability. ${ }^{59,60}$ High values of zeta potential correspond to higher electrical charge on the NPs surface, which causes strong repulsive force among the particles that prevent aggregates. In present study, we observed on the surface of SBT@AgNPs zeta potential value about $-29 \pm 0.11 \mathrm{mV}$ (Fig. 9c). The stability of SBT@AgNPs correlates well with higher surface charge as indicated by zeta potential value, therefore, based this results we concluded that

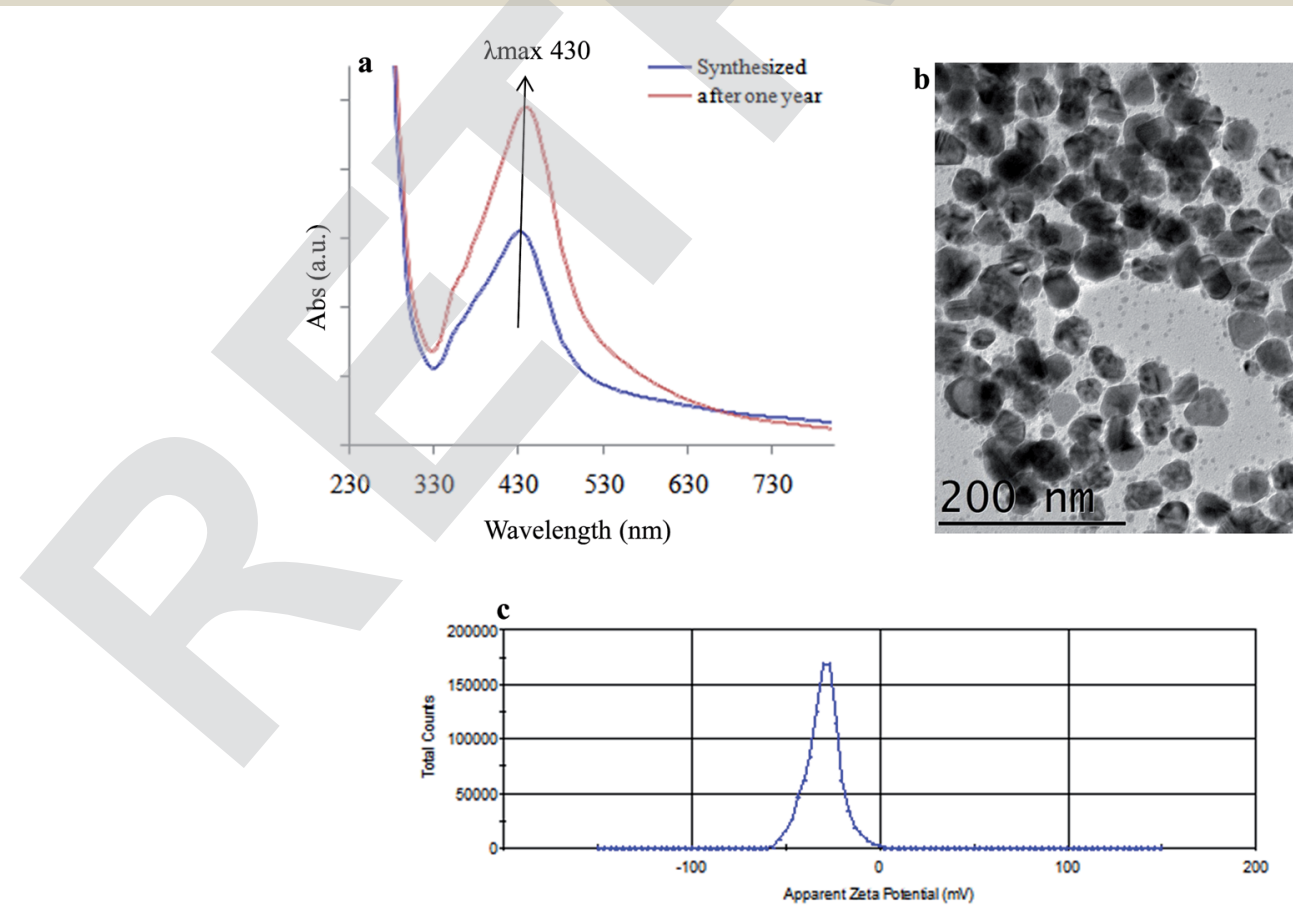

Fig. 9 Stability and longevity study of SBT@AgNPs. (a) UV-vis spectra showing unchanged SPR of ( $\lambda_{\max } 430 \mathrm{~nm}$ ) SBT@AgNPs before and after one year of synthesis (without dilution), (b) TEM image of SBT@AgNPs after one year of synthesis, (c) zeta potential after one year of synthesis as measured by DLS showing a value of $-29 \pm 0.11 \mathrm{mV}$, which is well in the range for higher stability. 
during storage period SBT@AgNPs did not get any aggregation. Therefore, the antibacterial remains unchanged similar to freshly prepared SBT@AgNPs. In consistence with these results, we therefore, suggest that SBT leaves extracts very good template for preparation of NPs. Interestingly, SBT@AgNPs were found featuring high stability and longevity, antibacterial, antioxidant potential. Hence the phytosynthesised SBT@AgNPs has immense potential for controlling bacterial infections in day to day life.

\section{Conclusions}

This study demonstrated that novel, green, eco-friendly, economically viable rapid preparation of SBT@AgNPs employing the leaves extracts of Seabuckthorn, which is stable and free from chemical agents and has potential to commercialize as effect tool of Gram positive and Gram negative bacterial infections. The phytosynthesised SBT@AgNPs were characterized by UV-vis, HRTEM, dynamic light scattering, zeta potential and FTIR, the results revealed that NPs spherical in shape and average size particle size of $\sim 10-40 \mathrm{~nm}$. The SBT@AgNPs has high surface charges $(-29 \pm 0.11 \mathrm{mV})$ and phytomolecules present in the leaves tightly anchored onto the surface of NPs, as a result, the prepared SBT@AgNPs has highly stable, featuring high antibacterial activity and more than 10 fold higher antioxidant activity then SBT leaves extract. Antibacterial efficacy was $>99.9 \%$ even after one-year storage. Further, this study demonstrated the preparation of antibacterial paper and nano-disinfects. Interestingly, SBT@AgNPs have higher antibacterial efficacy than the two commercially available medicated dressing materials, therefore, this study successfully developed effective antibacterial material, which can be facilely and rapidly prepared with high reproducibility, stability and low-cost. Hence, SBT@AgNPs may serve as a powerful antibacterial tool for controlling and prevention of currently emerging bacterial infections in the day to day life. We assume that the phytomolecules present in the leaves extract of Seabuckthorn may have significant role in the NPs synthesis and tightly anchored onto the surface of NPs, as a result, the NPs are more stable with immense antimicrobial properties. Therefore, further study may be undertaken to investigate the active phytomolecules present in the leaves extracts which is play the key role in NPs synthesis and antibacterial efficacy.

\section{Conflict of interest}

All the authors declare that there are no conflicts of interest.

\section{Acknowledgements}

The Authors are thankful to Defence Research and Developmental Organization (DRDO), New Delhi, India, for financial support. We are also thankful to The Director, Institute of Nanoscience and Technology, Mohali, Punjab, India for providing the TEM, FTIR, SEM, and Zeta facilities and $\mathrm{Mr}$ Sandeep Vashishth, Mr Naimat Kalim Bari, Ms. Rashmika Singh, Research fellows, INST, Mohali, India for their help during data acquisition. The authors are thankful to Mr Prince Vivek and Ms. Preeti Kumari Research fellows, DIHAR for antioxidant study. All the authors thankful to Dr Girish Mohanta, Dr Parveen Kaushik, CSIR-CSIO, Chandigarh, India for providing confocal microscopy facilities.

\section{References}

1 S. Stefania, M. Anna, B. Giovanna and C. Federica, Nanomedicine, 2016, 11, 1729-1744.

2 K. Melek, V. S. Virendra, F. A. Berta Esteban, U. Murat, S. Fernando, A. U. Deniz and W. Joseph, ACS Nano, 2015, 9(9), 9252-9259.

3 W. Yulan, W. Jiangshan, J. M. Richard, Z. Yanbin and Z. Yufeng, Nanoscale, 2016, 8, 11143-11152.

4 O. Cars, A. Hedin and A. Heddini, Drug Resist. Updates, 2011, 14, 68-69.

5 R. P. Mishra, E. Oviedo-Orta, P. Prachi, R. Rappuoli and F. Bagnoli, Curr. Opin. Microbiol., 2012, 15, 596-602.

6 J. Davies and D. Davies, Microbiol. Mol. Biol. Rev., 2010, 74, 417-433.

7 B. Katrijn and A. Arthur Van, Cent. Eur. J. Med., 2009, 4, 141155.

8 R. S. Kalhapure, N. Suleman, C. Mocktar, N. Seedat and T. Govender, J. Pharm. Sci., 2015, 104, 872-905.

9 A. L. Joseph, J. H. Joe and J. T. Raymond, Nat. Rev. Microbiol., 2013, 11, 371-384.

10 Z. Xi, F. Aleksandar, J. W. Radovic-Morenob, L. Robert and S. Jinjun, Nano Today, 2014, 9, 478-498.

11 M. D. Solmaz, M. Afsaneh, J. Samira, K. Khadejeh and A. Khosro, Adv. Pharm. Bull., 2005, 5(1), 19-23.

12 M. F. Amanulla, B. Kulandaivelu, G. Morukattu, Y. Ruchi, T. K. Pudupalayam and V. Ramasamy, Nanomedicine: Nanotechnology, Biology and Medicine, 2010, 6, 103-109.

13 Z. Yan, K. Ying, K. Subrata, D. C. Jeffrey and L. J. Hong, Nanobiotechnology, 2012, 10, 19-27.

14 R. Guogang, H. Dawei, W. C. Eileen, M. A. Cheng, P. R. Vargas-Reus and P. A. Robert, Int. J. Antimicrob. Agents, 2009, 33, 587-590.

15 X. Yanping, H. Yiping, L. I. Peter, J. Tony and S. Xianming, Appl. Environ. Microbiol., 2011, 77, 2325-2331.

16 K. Anna, D. María Suárez, R. David, B. Rafael, C. Sergio, Z. Inés, P. A. Juan, B. Coral, A. P. Vitor, S. Martins dos, G. Marcos Fernández and F. Manuel, Scientific Reports., 2014, 4, 4134-4142.

17 R. Dina, B. Kristine von, H. Albert and S. Hans-Georg, Appl. Environ. Microbiol., 2008, 74, 3764-3773.

18 O. C. Farokhzad and R. Langer, ACS Nano, 2009, 3, 16-20.

19 J. Shi, Z. Xiao, N. Kamaly and O. C. Farokhzad, Acc. Chem. Res., 2011, 44, 1123-1134.

20 V. Wagner, A. Dullaart, A. K. Bock and A. Zweck, Nat. Biotechnol., 2006, 24, 1211-1217.

21 J. Shi, A. R. Votruba, O. C. Farokhzad and R. Langer, Nano Lett., 2010, 10, 3223-3230.

22 M. L. Etheridge, S. A. Campbell, A. G. Erdman, C. L. Haynes, S. M. Wolf and M. Jeffrey, Nanomedicine: Nanotechnology, Biology and Medicine, 2013, 9, 1-14. 
23 Y. Longping, Y. Wenjing, W. Hongxia, Z. Hong and Z. Jianhao, RSC Adv., 2017, 7, 11355-11361.

24 Y. Roh, R. J. Lauf, A. D. McMillan, C. Zhang, C. J. Rawn, J. Bai and T. J. Phelps, Solid State Commun., 2001, 118(10), 529534.

25 B. Nair and T. Pradeep, Cryst. Growth Des., 2002, 2(4), 293298.

26 P. Mukherjee, A. Ahmad, D. Mandal, S. Senapati, S. R. Sainkar, M. I. Khan, R. Parishcha, P. V. Ajaykumar, M. Alam, R. Kumar and M. Sastry, Nano Lett., 2001, 1(10), 515-519.

27 P. Mukherjee, A. Ahmad, D. Mandal, S. Senapati, S. R. Sainkar, M. I. Khan, R. Ramani, R. Parischa, P. A. Ajaykumar, M. Alam, M. Sastry and R. Kumar, Angew. Chem., Int. Ed., 2001, 40(19), 3585-3588.

28 A. Ahmad, S. Senapati, M. I. Khan, R. Kumar, R. Ramani, V. Srinivas and M. Sastry, Nanotechnology, 2003, 14(7), 824828.

29 M. Kowshik, S. Arhtaputre, S. Kharrazi, W. Vogel, J. Urban, S. K. Kulkarni and K. M. Paknikar, Nanotechnology, 2003, 14, 95-100.

30 W. Shenton, T. Douglas, M. Young, G. Stubbs and S. Mann, Adv. Mater., 1999, 11(3), 253-256.

31 K. B. Narayanan and N. Sakthivel, Adv. Colloid Interface Sci., 2010, 156(1-2), 1-13.

32 K. N. Thakkar, S. S. Mhatre and R. Y. Parikh, Nanomedicine: Nanotechnology, Biology and Medicine, 2010, 6(2), 257-262.

33 S. Iravani, Green Chem., 2011, 13(10), 2638-2650.

34 S. S. Shankar, A. Rai, A. Ahmad and M. Sastry, J. Colloid Interface Sci., 2004, 275(2), 496-502.

35 A. K. Jha, K. Prasad and A. R. Kulkarni, Colloids Surf., B, 2009, 73(2), 219-223.

36 N. K. Upadhyay, M. S. K. Yogendra and G. Asheesh, Food Chem. Toxicol., 2010, 48, 3443-3448.

37 N. K. Upadhyay, M. S. K. Yogendra and G. Asheesh, Food Chem. Toxicol., 2010, 48, 3443-3448.

38 C. Garry, T. Kang Nee, W. Christophe and F. Jeffrey, Antioxidants, 2013, 2, 1-10.

39 P. Mulvaney, Langmuir, 1996, 12, 788-800.

40 M. Harshiny and M. Matheswaran, ACS Sustainable Chem. Eng., 2015, 3(12), 3149-3156.

41 S. H. H. Abdulrahman, K. Chandrasekaran, A. Abdulazees Parveez, T. Nooruddin, S. A. Naiyf, A. Sulaiman Ali and R. Ganasan, Sci. Rep., 2016, 6, 24312-24323.
42 B. Goutam, S. Sajal, G. Ranjan, B. Soma, C. M. Narayan, K. J. Shyamal, B. Bubun and R. Rajiv, Org. Med. Chem. Lett., 2014, 4, 18-28.

43 P. M. Sankar, Indian J. Chem., Sect. B: Org. Chem. Incl. Med. Chem., 2014, 53, 1255-1262.

44 J. B. Morons, J. L. Elechiguerra, A. Camacho-Bragado, K. Holt, J. B. Kourai, J. T. Ramirez and M. J. Yacaman, Nanotechnology, 2005, 16(10), 2346-2353.

45 J. Liu, D. A. Sonshine, S. Shervani and R. H. Hurt, ACS Nano, 2010, 4, 6903-6913.

46 C. Losasso, S. Belluco, V. Cibin, P. Zavagnin, I. Micetic, F. Gallocchio, M. Zanella, L. Bregoli, G. Biancotto and A. Ricci, Front Microbiol., 2014, 5(227), 1-9.

47 S. Sridhar, K. M. Rakesh, K. Satish, M. Mitali, G. Arnab, S. Mrutyunjay, V. S. Parlapalli, M. Harapriya, G. Chandan and G. Luna, Sci. Rep., 2016, 6, 24929-24944.

48 A. J. Kora and R. B. Sashidhar, J. Antibiot., 2014, 1-10.

49 P. Jayanta Kumar and B. Kwang-Hyun, Front Microbiol., 2017, 8, 167-180.

50 E. Hoda, R. Hamid and N. Saeed, Adv. Nat. Sci.: Nanosci. Nanotechnol., 2017, 8, 025004-025013.

51 B. Srinivasan, J. Phylogenet. Evol. Biol., 2015, 3, 10001461000151.

52 A. R. Allafchian, S. Z. Mirahmadi-Zare, S. A. H. Jalali, S. S. Hashemi and M. R. Vahabi, J. Nanostruct. Chem., 2016, 6, 129-135.

53 A. Shakeel, M. A. Saifullah, S. BabuLal and I. Saiqa, J. Radiat. Res. Appl. Sci., 2016, 9, 1-7.

54 A. Theresa and G. K. Derek, Environ. Sci. Technol., 2011, 45(5), 1992-1998.

55 S. Park, N. Mohanty, J. W. Suk, A. Nagaraja, J. An, R. D. Piner, W. Cai, D. R. Dreyer, V. Berry and R. S. Ruoff, Adv. Mater., 2010, 22, 1736-1740.

56 H. Wenbing, P. Cheng, L. Weijie, L. Min, L. Xiaoming, L. Di, H. Qing and F. Chunhai, ACS Nano, 2010, 4(7), 4317-4323.

57 L. R. Prior, X. Wu and K. Schaich, J. Agric. Food Chem., 2005, 53, 4290-4302.

58 E. E. Elias, E. F. Omolola, C. E. Anthony, C. O. Damian and E. E. Eno, Molecules, 2017, 22, 701-721.

59 M. F. Melendrez, G. Cardenas and J. Arbiol, J. Colloid Interface Sci., 2010, 346, 279-287.

60 S. Renu, K. Arunachalam, P. Annamalai, K. Selvaraju, S. Kanchi, B. Shivashangari and R. Vilwanathan, Colloids Surf., B, 2013, 108, 80-84. 